\title{
REACH for Commercialization: Narrowing the Gender Gap in Technology Transfer
}

\author{
Mary C. Juhas and Caroline E. Crisafulli
}

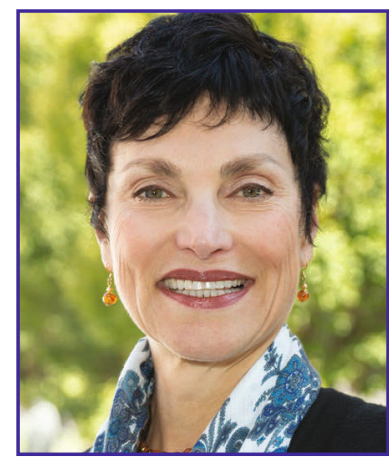

Mary C. Juhas

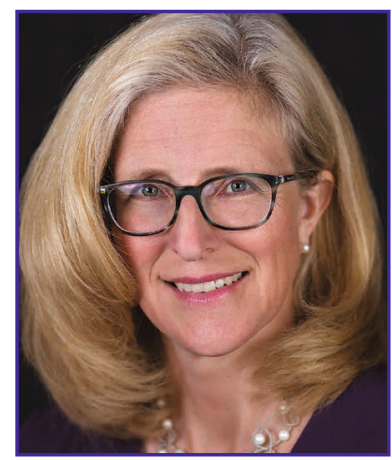

Caroline E. Crisafulli

\section{Background}

A 2019 U.S. Patent and Trademark Office report revealed that over the last decade, all-female teams on patents represented roughly $4 \%$ of issued patents. As shown in Table I, there is a persistent and wide gender gap in patent activity across all economic sectors including corporations, academia, government, and nonprofits. The greatest disparity is found in the corporate sector. While the patents with at least one female inventor have increased from 4\% in 1976 to $21 \%$ in 2016 , the number of unique women inventors (considering those with multiple patents), shown as "women inventor rate," has remained flat at about $10-12 \%$ since 2000 .

Research reveals that this imbalance stems predominantly from 1 ) inadequate formal and informal networks, and 2) the "service tax," which disproportionately disadvantages women with extra work burdens that routinely go unrecognized and uncompensated..$^{2-3}$ This is particularly true for women of color who experience the service tax double bind. These realities of the job are exacerbated by deeply entrenched cultural norms that are typically unspoken but have significant

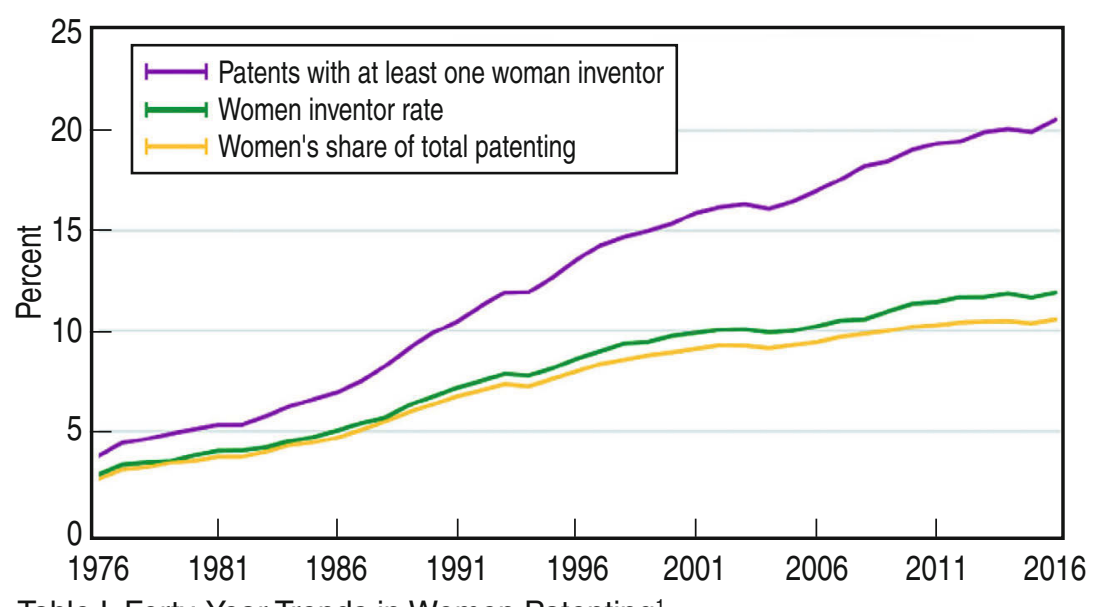

impact. Women are uncomfortable with the self-promotion necessary to stand out and move ideas forward. Those who do risk engaging in self-promoting behavior earn unflattering labels, sometimes from other women. Women often avoid the risk of representing their gender if they fail. This is especially the case when they engage in professional activities perceived as straying outside the established expectations and requirements of their job. Indeed, invention disclosures and patent applications - the precursors of an awarded patent - are not guarantees of success in the tenure process, promotion, or recognition among peers in academia or in any organization.

\section{REACH for Commercialization ${ }^{\mathrm{TM}}$}

REACH for Commercialization ${ }^{\mathrm{TM}}$ is a year-round, cohort-based program designed to address the persistent gender gap in technology transfer, patenting, and entrepreneurial activities. REACH consists of a series of interactive workshops, formal and informal networking opportunities, and individual mentoring. The program is designed to amplify the impact of ResEArCH, fasttrack academic discovery for the benefit of society, and enhance professional development.

Initially known as "Project REACH," the program emerged as the signature initiative of a National Science Foundation ADVANCE Institutional Transformation grant awarded to The Ohio State University (OSU) in 2008. The five-year grant marked the design and launch of a formal program to address the gender chasm in technology transfer at OSU. The year 2020 marks the sixth cohort to participate in REACH. Since its inception, the program has 
"Participants are not required to have a commercial

idea in mind-only the desire to learn and explore

commercialization as another pathway to

disseminate their research."

-Mary C. Juhas and Caroline E. Crisafulli expanded beyond faculty to include research staff, postdoctoral scholars, and select graduate students for a total of 110 women who have participated in the program. Altogether, they are associated with 317 invention disclosures, 307 patent applications, 96 issued patents, and nine startups. Participation is open to women in all colleges and departments and all stages of technology transfer. Participants are not required to have a commercial idea in mindonly the desire to learn and explore commercialization as another pathway to disseminate their research.

While entrepreneurial "boot camp" programs are a valued component of building entrepreneurial capacity, REACH provides additional avenues for women to excel in commercialization and innovation. The program is designed as a complement to the more lock-step boot camps by meeting women where they are in their professional career and in the commercialization process. The result is a highly personalized experience that addresses the spectrum of academic innovation.

Networks are at the core of the program. REACH proactively expands the participants' commercialization ecosystem and animates innovation and collaboration. Prior participants are invited back to engage in all events, and they serve as authentic and approachable role models and near peers. The REACH program has steadily evolved into a flexible, supportive, and continuous resource. On-ramps and off-ramps are built into the program to mitigate barriers and maximize participation. The REACH program works because:

1. REACH is a customized experience. Through individual consultations with the director of innovation and an extensive network of committed mentors, entrepreneurs, and resources, REACH provides personalized pathways for technology transfer. REACH recognizes that stories of failure are as valuable as success stories. It is important for participants to understand the challenges faced in the commercialization process and how to access tools to persevere through those challenges.

2. REACH openly addresses women's lack of self-promotion. REACH encourages self-awareness skills, so participants become comfortable in articulating the need to access money, power, and influence in order to move forward.

\section{REACH Core Workshops}

Four Core Workshops cover a broad overview of the technology transfer and commercialization process, as outlined here.

\section{Visioning Impact from Research}

Startup founders share their journeys of balancing the demands of an academic career, tenure, promotion, research, technology transfer, and launching a company.

\section{Learning the Landscape}

Academic leaders underscore the value of entrepreneurial activity as an important complement that aligns well with and strengthens the traditional linear academic trajectory. Technology Commercialization team members engage with REACH participants individually to describe the commercialization process, initiate relationships, and plan next steps.

\section{Building a Team}

Experienced academic innovators emphasize the importance of building a strong team, with diverse skill sets that complement the innovator's expertise. The big takeaway is the innovator isn't responsible for all sides of technology transfer; her primary role is technical expert.

\section{Understanding the Funding Life Cycle}

Representatives from a variety of funding sources describe the process and the appropriate time to engage with specific funding mechanisms. 


\section{REACH Constellation Workshops}

Constellation workshops explore the core workshop themes in greater detail. The topics featured in the constellation workshops are designed expressly by the needs and interests of the participants. Examples of constellation workshops include:

- Increasing Research Visibility

- Creating a Professional Brand

- Optimizing Professional Conferences

- Introduction to Intellectual Property Licensing

- Introduction to New Venture Creation

- Customer Discovery

- Copyrights and Trademarks

- Patents and Patent Searches

\section{Lessons Learned}

1. Personal invitation to participate is the most effective way to recruit.

2. Despite the fact that participants are highly accomplished in their field, they feel embarrassed about an unfamiliarity with the technology transfer process.

3. Schedule events during work hours to maximize participation.

4. Female role models and mentors are most effective.

5. The program became markedly richer and more productive when women from all academic disciplines were invited.

6. New interdisciplinary collaborations routinely initiate within and among REACH cohorts.

7. Follow each workshop with short flash surveys to enhance personalized programming. Make adjustments in real time based on the needs and feedback of the cohort.

8. Survey tools developed under Institutional Review Board protocol informed the core workshop topics. Pre- and post-program surveys (19 questions) have been refined over the years.

9. The COVID-19 pandemic has created an opportunity to reimagine programming and improve the REACH network. All workshops are currently held virtually and recorded, increasing flexibility and accessibility.

\section{Next Steps}

We are seeking partners for a pilot to translate the REACH program to other academic institutions, corporations, and national laboratories. These new partnerships will expand the community of women innovators, initiate collaborations, and introduce new role models and mentors. Additionally, we hope to continue to expand beyond the STEM and health sciences disciplines to include more participants from social and behavioral sciences, arts, and humanities, as well as the participation of postdoctoral scholars.

\section{Endnotes}

1. U.S. Patent and Trademark Office, Office of the Chief Economist, "Progress and Potential: A Profile of Women Inventors on U.S. Patents" (2019).

2. "Gender Diversity in Innovation Toolkit," IPO Law Journal, Intellectual Property Owners Association, (2019).

3. A. lancu and L.A. Peter, U.S. Patent and Trademark Office, "Report to Congress pursuant to P.L. 115-273, The SUCCESS Act of 2018 (Study of Underrepresented Classes Chasing Engineering and Science Success)" (2019).

Mary C. Juhas is associate vice president in the Office of Research and clinical professor of materials science and engineering at The Ohio State University (OSU). Juhas is a past chair of the TMS Women in Materials Science and Engineering Committee (now the Diversity, Equity, and Inclusion Committee).

Caroline Crisafulli is director of innovation for Ohio State ADVANCE at OSU and is listed on seven issued U.S. patents.

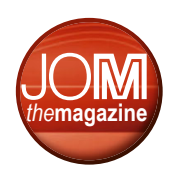

